\title{
Mosaicism for structural non-centromeric autosomal rearrangements in disease- defined carriers: sex differences in the rearrangements profile and maternal age distributions
}

\author{
Natalia V. Kovaleva ${ }^{{ }^{*}}$ and Philip D. Cotter ${ }^{2,3}$
}

\begin{abstract}
Background: Mosaicism for an autosomal structural rearrangement (Rea) associated with clinical manifestation of chromosomal imbalance is rare. Consequently, there is a lack of basic epidemiological characterization of this kind of mosaicism, such as population rate, cytogenetic profile of Reas involved, maternal age distribution, and sex (male to female) ratio among Rea carriers. The objectives of the present study were: (i) determination of the Rea profile in clinically affected individuals, (ii) comparative analysis of the cytogenetic profile and involvement of single chromosomes to rearrangements in affected and previously reported asymptomatic carriers, (iii) analysis of the male/female ratio in carriers of various types of Rea, and, (iv) examination of parental ages distributions according to carriers' sex.

Results: Two hundred and forty six disease-defined cases of mosaicism for autosomal non-centromeric Rea with a normal cell line of known sex were identified from the literature. There was a significant difference in single chromosome involvements compared to structural rearrangements between affected and asymptomatic carriers of unbalanced Rea, $p=0.0030$. In affected carriers, chromosome 18 was most frequently involved in structural rearrangements (12.6\% of 246 instances). The least frequently rearranged were chromosomes 16 and 21 $(0.8 \%$ and $1.2 \%$, respectively). In asymptomatic carriers, the most frequently rearranged were chromosomes 5 and 21 (13\% of 51 instances each). Among carriers of "loss" or "gain/loss" of genomic material, a female predominance was observed ( $50 \mathrm{M} / 89 \mathrm{~F}$, different from population ratio of 1.06 at $p=0.0002)$. Carriers of either "gain" or balanced Rea demonstrated typical male predominance (41 M/30 F and $18 \mathrm{M} / 16 \mathrm{~F})$, not different from 1.06. Maternal and paternal ages were reported in 129 and in 109 cases, respectively. There was a significant difference in maternal age distribution between male and female carriers, with mean maternal age of 25.2 years vs 28.3 years $(p=0.032$ ). However, there was no difference in paternal age, with mean paternal age of 29.4 in both groups.
\end{abstract}

Conclusion: The data suggested that structural rearrangements of certain chromosomes involved in mosaicism may not be tolerated by the embryo, while others have higher survival prospects. Maternal age appears to be a risk factor for somatic mosaicism of structural Rea in female offspring or might cause an adverse effect on male embryo viability.

Keywords: Segmental somatic mosaicism, Non-centromeric autosomal rearrangement, Genomic imbalance, Sex ratio, Maternal age, Paternal age

\footnotetext{
* Correspondence: kovalevanv2007@yandex.ru

${ }^{1}$ Academy of Molecular Medicine, Mytniskaya str. 12/44, St. Petersburg

191144, Russian Federation

Full list of author information is available at the end of the article
} 


\section{Background}

Somatic chromosomal mosaicism, the presence of two or more cell lines with different chromosomal constitution, is a common phenomenon in humans [1]. However, mosaicism for structural chromosomal rearrangements (N/Rea, normal line/rearrangement) is rarely reported. Consequently, there is a lack of basic epidemiological characterization of this category of mosaicism, such as population rate, cytogenetic profile of the Reas involved, maternal age distribution, and sex ratio (SR, male to female ratio) among the carriers of Reas.

Depending on factors such as the severity of genomic imbalance, the degree of mosaicism and tissue distribution, the carrier of a somatic mosaicism may be asymptomatic or may present with a variable phenotype. A recent study of patients with somatic/gonadal mosaicism described differences in cytogenetic profile among asymptomatic and affected individuals [2]. In addition, the study revealed a strong female prevalence among both affected and asymptomatic carriers of somatic/gonadal mosaicism for unbalanced Rea, unlike the typical male prevalence among carriers of balanced Rea. However, the number of affected carriers was low (2 M/10 F), not allowing for detailed evaluation of single chromosome involvement in various type of abnormalities and sex ratio among carriers of various types of Reas.

Therefore, the objectives of the present study were: (i) determination of the Rea profile in clinically affected carriers, (ii) comparative analysis of the cytogenetic profile and involvement of single chromosomes to structural rearrangements in affected and previously reported asymptomatic carriers, (iii) analysis of the sex ratio ratio in affected carriers of various types of Rea, and (iv) examination of the effect of parental ages.

\section{Methods}

We reviewed reports in the literature of mosaicism for N/ Rea cases detected microscopically (up to 850-band level of resolution, i.e. $\geq 5 \mathrm{Mb}$ ), by conventional cytogenetics or by molecular cytogenetics. The cases were identified from various sources including PubMed. Reports of N/Rea affected carriers of unknown sex were excluded from the study. According to Barber [3], individuals were considered phenotypically affected when any type of phenotypic anomaly was reported, even if the etiological role of the chromosome abnormality in the same individual was questionable. From the sample collected, we further excluded cases of Rea with both breakpoints localized at pericentromeric regions, because of the strong female preponderance among carriers of such mosaicism $[4,5]$. Cases of familial instability were also excluded from the study. The selection criteria was any rearrangement identified by cytogenetic or molecular cytogenetic techniques.
Two hundred and forty six cases of N/Rea, along with the data on their chromosome constitution, patient's's age at testing/ascertainment, parental ages at the birth of the proband, proportion of abnormal cell line(s), and the indication for testing are tabulated in Additional files 1, 2, 3, 4, 5, 6 and 7: Tables S1-S7.

Rea were classified as loss, gain, and loss/gain of genomic material. Deletions were classified as losses, duplications and additional material were classified as gains, and derivative chromosomes, isodicentrics, complex Reas, and cases with two abnormal cell lines, one of which with deletion, another one with duplication, were classified as "loss/gain". In some instances, derivatives and other rearrangements were considered as apparent or suggestive "gain" or "loss".

Data were analyzed using open access software listed in the Additional file 8: Table S8. References for Additional files $1,2,3,4,5,6,7$ and 8 are listed in the Additional file 9: Supplemental References.

\section{Results and discussion N/Rea profile}

A summary of the data are presented in Table 1. The prevalence of deletions over duplications in affected carriers is a well-known phenomenon. A study carried out

Table 1 Cytogenetic profile of mosaic structural rearrangements

\begin{tabular}{|c|c|c|c|c|}
\hline \multirow[t]{2}{*}{ Type of rearrangement } & & \multicolumn{3}{|l|}{ Sex } \\
\hline & & Males & Females & $\overline{\text { Total }}$ \\
\hline \multirow[t]{2}{*}{ Deletions } & $\begin{array}{l}\text { excluding del(13) } \\
\text { associated with } \\
\text { retinoblastoma }\end{array}$ & 20 & 45 & 65 \\
\hline & $\begin{array}{l}\text { del(13) associated with } \\
\text { retinoblastoma }\end{array}$ & 5 & 8 & 13 \\
\hline Duplications & & 23 & 16 & 39 \\
\hline \multirow[t]{3}{*}{ Rings } & apparently deleted & 11 & 15 & 47 \\
\hline & no apparent deletion & 10 & 10 & \\
\hline & uncertain & 1 & & \\
\hline \multirow{3}{*}{$\begin{array}{l}\text { Unbalanced } \\
\text { translocations }\end{array}$} & loss & 1 & & 23 \\
\hline & gain & 6 & 7 & \\
\hline & gain/loss & 3 & 6 & \\
\hline \multirow{3}{*}{$\begin{array}{l}\text { Other unbalanced } \\
\text { rearrangements }\end{array}$} & loss & & 1 & 29 \\
\hline & gain & 8 & 5 & \\
\hline & gain/loss & 5 & 10 & \\
\hline \multirow{2}{*}{$\begin{array}{l}\text { Apparently balanced } \\
\text { rearrangements }\end{array}$} & inversions & 2 & 1 & 13 \\
\hline & $\begin{array}{l}\text { reciprocal } \\
\text { translocations }\end{array}$ & 5 & 5 & \\
\hline \multirow{3}{*}{$\begin{array}{l}\text { Rescued } \\
\text { rearrangements }\end{array}$} & loss & 1 & 3 & 17 \\
\hline & gain & 5 & 2 & \\
\hline & gain/loss & 5 & 1 & \\
\hline Total & & 111 & 136 & 246 \\
\hline
\end{tabular}

ancluding 3 deletions, 2 duplications, 2 rings, 7 unbalanced translocations, and 2 other unbalanced rearrangements 
by FISH on semen samples from control donors showed similar deletion and duplication frequencies of chromosomal regions $7 \mathrm{q} 11.23,15 \mathrm{q} 11 \mathrm{q} 13$, and 22q11 [6] while studies on affected carriers revealed a clear excess of deletions of these regions $[7,8]$. Therefore, this phenomenon may be explained by phenotypic silence of some chromosomal regions when duplicated.

Balanced rearrangement carriers among 229 affected mosaic patients (excluding 17 with rescued rearrangements) were observed at a frequency of $6 \%$, similar to rates observed in affected non-mosaic carriers. Detailed screening of microscopically balanced de novo rearrangements using high-resolution genome-wide analysis detected a chromosome imbalance in $37 \%$ of patients. In $49 \%$ of these patients, the imbalances were located in one or both breakpoint regions while the others were found elsewhere in the genome [9], being therefore just coincidental or concomitant with a balanced rearrangement.

To compare the profiles in affected and asymptomatic carriers (Table 2), we excluded one abnormality with a large cohort and specific indications from the profile analysis (13 cases of interstitial del(13) associated with retinoblastoma) and sixteen rescued rearrangements because of exclusion of such cases from the previously reported group of asymptomatic carriers. Balanced Rea (reciprocal translocations and inversions) were not included in the analysis, comprising $51 \%$ of the cases in asymptomatic carriers [2]. Of the remaining 203 cases, there were 65 deletions (32\%), 39 duplications (19\%), 48 rings (24\%), 23 unbalanced translocations (11\%), and 28 other Reas (14\%). There is a significant concordance of the profile of mosaic unbalanced Reas in affected carriers with the profile found in asymptomatic carriers of somatic/gonadal mosaicism, with some prevalence of deletions in the latter group. However, it should be mentioned that among affected carriers of mosaic ring chromosomes, mosaics for deleted ring chromosomes were found more frequently compared to asymptomatic carriers (55\% vs $14 \%$ ). Because of the small number of samples, this difference does not reach statistical significance, and additional cases are required for a conclusion.

The distribution of single chromosome across various types of rearrangements is not uniform, as summarized in Table 3. For example, chromosome 18, being the most frequent among both deleted chromosomes and rings
(12 and 10 cases, respectively), is found to have no duplications. In contrast, chromosomes 1 and 12 are more frequently found to be duplicated than deleted ( 6 and 7 cases vs 1 and 1). Chromosomes 21 and 16 appeared to be the least subjected to rearrangements, with only 2 and 3 of 246 instances ( 0.8 and $1.2 \%$, respectively).

To compare single chromosome involvement to structural rearrangements between affected and asymptomatic carriers, we have removed balanced rearrangements (Table 4). There is a statistically significant difference between the groups at $p=0.0030$. Such analysis is of potential meaning for evaluation of fitness of mosaic preimplantation embryos. It might be possible that rearrangements of certain chromosomes (for example, deletion of chromosome 18) are not tolerated by the embryo while others, being involved in segmental mosaicism (for example, chromosomes 5 and 21), might have good prospects. However, again, more cases should be collected for such study. Ultimately, lethality would be a function of critical genetic content. Genotype-phenotype comparisons are more complicated in mosaic cases, compounded by the level of mosaicism and the tissue distribution.

\section{Frequency of detection of somatic N/Rea mosaicism}

The data suggests that somatic mosaicism may be more frequent than expected: 3 mosaics were detected among 32 carriers of del(5) (q14) when examining at least 125 metaphases in each individual [10]. 2 of 16 cytogenetically visible $11 \mathrm{p} 13$ deletions and 3 cryptic $11 \mathrm{p} 13$ deletions were mosaic [11]. Of 27 patients with del(16) (p11.2), two were mosaics [12], and 25 mosaics were detected among $126 \operatorname{del}(13)$ (q14) reports [13]. Cytogenetic analysis showed a del(15) (q11-13) in 12 patients in whom the clinical diagnosis was certain; in two there was mosaicism, and one patient also had a $t(7 ; 15)$ translocation [14]. In 17 cases of monosomy of $18 \mathrm{q} 12.3$ one was a mosaic with a normal cell line [15]. Among 29 carriers of ring chromosomes, three had a normal cell line [16], and among six patients with a $r(22)$, one was mosaic for a normal cell line [17]. In 1966-1991, 10 patients with $\mathrm{r}(18)$ were diagnosed among $82,000 \mathrm{pa}$ tients karyotyped for constitutional reasons; three of these 10 presented with mosaicism for normal line [18].

Table 2 Cytogenetic profile of mosaicism for structural rearrangement in affected and asymptomatic patients

\begin{tabular}{lllllll}
\hline Group & No of & \multicolumn{4}{l}{ Type of chromosome rearrangement, $n(\%)$} \\
\cline { 3 - 7 } & carriers & Deletions & Duplications & Rings & Unbalanced translocations & Other rearrangements \\
\cline { 5 - 7 } Affected (present study) & 203 & $65(32 \%)$ & $39(19 \%)$ & $47(23 \%)^{c}$ & $23(11 \%)$ & $29(14 \%)$ \\
Asymptomatic (Kovaleva, Cotter, 2016) & 45 & $18(40 \%)$ & $9(20 \%)$ & $9(20 \%)^{d}$ & $4(9 \%)$ & $5(11 \%)$ \\
\hline
\end{tabular}

aexcluding cases of apparently balanced and rescued rearrangements

bexcluding 13 cases of del(13q) associated with retinoblastoma

c $55 \%$ of apparently deleted rings

${ }^{\mathrm{d}} 14 \%$ of apparently deleted rings 
Table 3 Distribution of single chromosomes according to type of rearrangements

\begin{tabular}{|c|c|c|c|c|c|c|c|}
\hline Chromosome & Deletions $^{a}$ & Duplications & Rings & $\begin{array}{l}\text { Unbalanced } \\
\text { translocations }\end{array}$ & $\begin{array}{l}\text { Other unbalanced } \\
\text { rearrangements }\end{array}$ & $\begin{array}{l}\text { Balanced } \\
\text { rearrangements }\end{array}$ & Total \\
\hline 1 & 1 & 6 & 0 & 0 & 1 & 3 & 11 \\
\hline 2 & 1 & 2 & 3 & 2 & 0 & 2 & 10 \\
\hline 3 & 2 & 3 & 0 & 2 & 3 & 1 & 11 \\
\hline 4 & 4 & 1 & 5 & 1 & 1 & 2 & 13 \\
\hline 5 & 2 & 2 & 0 & 1 & 3 & 0 & 7 \\
\hline 6 & 1 & 0 & 2 & 3 & 0 & 3 & 9 \\
\hline 7 & 6 & 1 & 1 & 2 & 3 & 1 & 13 \\
\hline 8 & 4 & 1 & 2 & 3 & 2 & 1 & 13 \\
\hline 9 & 0 & 0 & 2 & 5 & 0 & 1 & 8 \\
\hline 10 & 0 & 0 & 0 & 3 & 1 & 0 & 4 \\
\hline 11 & 7 & 2 & 0 & 1 & 1 & 1 & 12 \\
\hline 12 & 1 & 7 & 1 & 1 & 4 & 2 & 16 \\
\hline 13 & 6 & 1 & 5 & 2 & 0 & 0 & 14 \\
\hline 14 & 4 & 2 & 1 & 1 & 4 & 1 & 13 \\
\hline 15 & 4 & 3 & 2 & 3 & 2 & 1 & 15 \\
\hline 16 & 1 & 0 & 0 & 2 & 0 & 0 & 3 \\
\hline 17 & 3 & 6 & 2 & 0 & 0 & 2 & 12 \\
\hline 18 & 12 & 0 & 10 & 4 & 5 & 0 & 31 \\
\hline 19 & 2 & 0 & 3 & 1 & 1 & 1 & 8 \\
\hline 20 & 2 & 2 & 0 & 0 & 0 & 1 & 5 \\
\hline 21 & 0 & 0 & 2 & 0 & 0 & 0 & 2 \\
\hline 22 & 2 & 0 & 7 & 2 & 0 & 1 & 12 \\
\hline Total & 65 & 39 & 48 & 39 & 31 & 24 & 246 \\
\hline Proportions & $0.200 .26_{0.35}$ & $0.110 .16_{0.23}$ & $0.130 .20_{0.27}$ & $0.110 .16_{0.23}$ & $0.070 .13_{0.18}$ & $0.060 .10_{0.16}$ & 1,00 \\
\hline$P$-value & $2 \cdot 10-6$ & & & & & & \\
\hline
\end{tabular}

a excluding 13 cases of del(13q14) associated with retinoblastoma

A recent study on the frequency of mosaicism for balanced Rea, showed that mosaicism for inversions was the most common $(3 / 103=2.9 \%)$ followed by mosaicism for reciprocal translocations $(7 / 453=1.5 \%)$, while mosaicism for Robertsonian translocations was the least common $(2 / 265=0.8 \%)$ [2]. These data obtained from the analysis of studies on a total of 56,760 patients with reproductive failures were consistent with corresponding data from a report on a constitutional chromosome analysis in 74,306 consecutive patients [19].

Diagnosis of whole chromosome or structural Rea mosaicism is likely under-reported due to low level mosaicism. Sciorra et al. [20] reported that it is the policy of most clinical genetic laboratories to count only 15 or 20 cells and to analyze 2 or 3 metaphases for work up of patients. This laboratory approach is due to various time and financial constraints, as well as the assumption that mosaicism for a structural rearrangement, while theoretically possible, is an unlikely event". However, the data accumulated in the literature indicated that mosaicism might be more frequent than recognized currently.

\section{Parental and cell origin of N/Rea mosaicism}

The parental origin of chromosomes involved in mosaic rearrangements was reported in few cases, being paternal in six instances [21-25] and maternal in three instances [25-27]. Additionally, the paternal origin of the abnormal chromosome was reported in two carriers of gonadal mosaicism [28, 29], yielding to cumulative figures of eight paternally derived rearrangements vs three maternally derived rearrangements. Theoretically, if mosaicism arises mostly post-zygotically, then paternally and maternally derived rearrangements are expected to have equal frequency. However, at present, there is still insufficient data to allow any certain conclusions on whether there is a bias in parental origin of postzygotic rearrangements.

The preferential paternal origin was reported for various types of de novo non-mosaic unbalanced structural 
Table 4 Distribution of single chromosomes in affected and asymptomatic patients

\begin{tabular}{|c|c|}
\hline Affected $^{\mathrm{a}}$ & Asymptomatic $^{\mathrm{b}}$ \\
\hline \multicolumn{2}{|l|}{8} \\
\hline 8 & 2 \\
\hline 10 & 3 \\
\hline 12 & 3 \\
\hline 8 & $7(13 \%)$ \\
\hline 6 & 1 \\
\hline \multicolumn{2}{|l|}{13} \\
\hline 12 & 3 \\
\hline \multicolumn{2}{|l|}{7} \\
\hline 4 & 1 \\
\hline 11 & 1 \\
\hline 14 & 1 \\
\hline 14 & 3 \\
\hline 12 & 3 \\
\hline 14 & 3 \\
\hline 3 & 1 \\
\hline 11 & 3 \\
\hline 31 (14\%) & $2(4 \%)$ \\
\hline 7 & 1 \\
\hline 4 & 3 \\
\hline 2 & $7(13 \%)$ \\
\hline 11 & 3 \\
\hline 222 & 51 \\
\hline
\end{tabular}

axcluding balanced rearrangements (translocations and inversions)

bexcluding 13 cases of del(13q14) associated with retinoblastoma

rearrangements: Wolf-Hirshchorn syndrome-associated rearrangements [30], del 18p- [31], del 22q13.3 [32], and a preponderance of paternally derived deletions $5 \mathrm{p} 14$ were reported in two studies [33,34]. In addition, the majority of de novo cytogenetically balanced reciprocal translocations are of paternal origin [35]. Preferential formation in the paternal germline were detected for de novo balanced complex chromosome Reas [36]. High rates of de novo $15 \mathrm{q} 11 \mathrm{q} 13$ inversions was found in human spermatozoa [37]. A recent study using array comparative genome hybridization confirmed a significant paternal bias for de novo structural variations by any mechanism in 118 individuals with intellectual disability [38].

Mosacism with the presence of a normal cell line is commonly assumed to result from postzygotic errors. However, there is evidence that such rearrangements may originate during meiosis or may be inherited. In such cases, there should be postzygotic rescue events leading to formation of normal cell lines. Recently, Robberecht et al. [25] demonstrated that two of nine cases with mosaic segmental structural imbalances $(>15 \%)$ resulted from meiotic errors, followed by multiple parallel trisomy rescue events.

Cases of proved or presumptive rescued rearrangements together with a formation of normal cell line are summarized in Additional file 7: Table S7. The majority of the mosaics for inherited Rea were not evaluated for chimerism. However, as there was sex concordance between normal and abnormal cell lines the presence of chimerism is unlikely; in chimerism some cases would be expected to be sex discordant. In addition, chimerism is an extremely rare event.

An unusual finding was the comparatively high rate of involvement of chromosome 11 in rescue events, with four cases of ten. Moreover, in one of them, the rescue appeared to be familial since the mother was a mosaic for the same abnormality with UPD for a deleted region [39]. Apparent familial tendency to rescue was reported by Juberg et al. [40] who described two sibs with mosaicism for a paternally transmitted abnormality.

All cases of mosaicism for de novo rearrangements had been evaluated to investigate the mechanisms of the rearrangement formation (Additional file 7: Table S7). The parental origin of the rearranged chromosome resulted from a paternal meiotic error in four cases $[25,41-43]$ and maternal in three cases $[24,44,45]$.

\section{Male to female ratio}

The male to female ratio was analyzed across various types of rearrangements presented in Table 1 and showed significant variation depending on the type of Rea. Female predominance was observed in carriers of either "loss" or "gain/loss" Rea (50 M/89 F, different from population ratio of 1.06 at $p=0.0002$. Carriers of either apparent "gain" or apparent balanced Rea (including rings without apparent deletion) demonstrated absence of female predominance (41 M/30 F and $18 \mathrm{M} / 16 \mathrm{~F}$, respectively) not statistically different from population ratio of 1.06 .

A recent study reported a strong female predominance among asymptomatic carriers of somatic/gonadal mosaicism for unbalanced Rea. Since no distortion in sex ratio was found among carriers of mosaicism for balanced Rea, a male-specific selection against abnormal cells in early embryo development was proposed [2]. However, results from the present study might indicate that selection against abnormal cells, if it exists, depends on the type of the Rea and the size of genomic imbalance. Apparently, duplications resulting in gains of chromosomal material, if not occurring more frequently in males, are not selected against in males. Similarly, both loss and gain/loss, if not occurring more frequently in females, are more tolerated in females than in males. Again, such unexpected and intriguing findings require further study. 


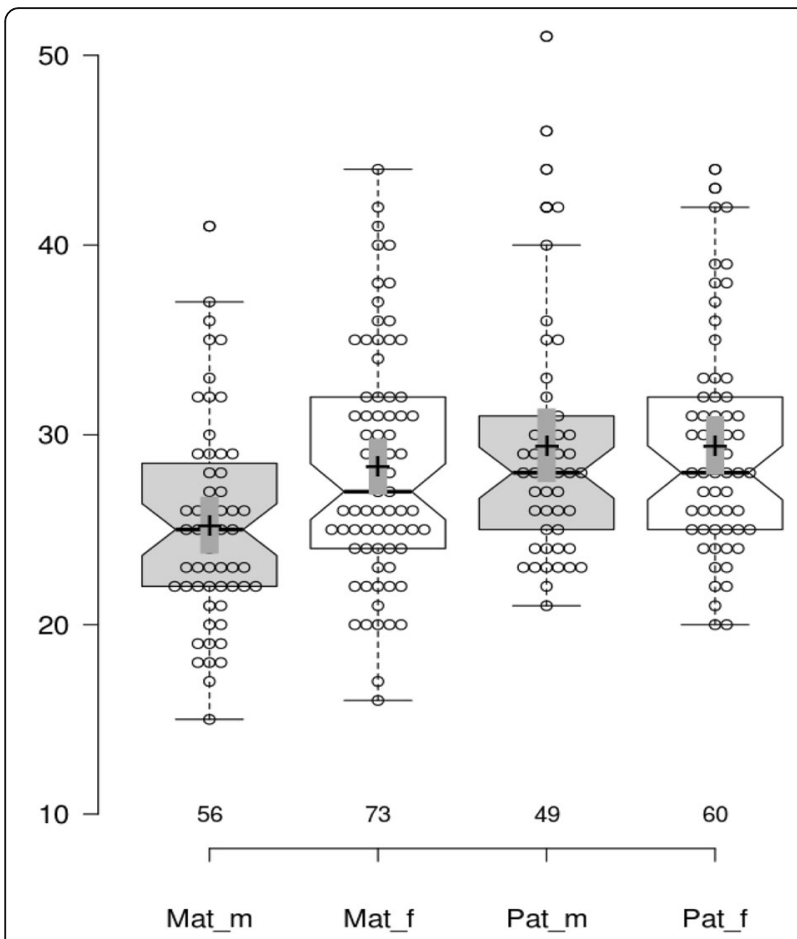

Fig. 1 Notched boxplots for the ages of mothers (Mat) and fathers (Pat) of males $(m)$ and females $(f)$. Numbers at the $x$-axis are sample sizes

\section{Parental ages}

Maternal and paternal ages were reported in 129 and 109 cases, respectively. Surprisingly we have identified a difference in maternal age distributions between male and female carriers, with mean maternal age of 25.2 years $(95 \%$ CL 23.8-26.6) vs 28.3 years (95\% CL 26.9-29.7), respectively, the difference is significant at $p=0.032$. However, there is no difference in paternal age, with mean age of 29.4 years in both male and female carriers (see Figs. 1 and 2). Sex ratio displays an apparent tendency to decrease with increase of maternal age, from 4.7 in the group of $<20$ year to 0.3 in the group of aged 40 year and older (Table 5). No such trend was found when analyzing sex ratio according to paternal ages.
We are not aware of any previous publications reporting maternal age distribution differences between carriers of segmental mosaicism in relation to carriers' sex. This unexpected finding suggests an effect of agerelated factors either on the postzygotic stability of female genomes or on intrauterine selection against affected male embryos, or on the male-specific selection against abnormal cells in early embryo development. A high intrauterine lethality of male carriers is less likely because of a lack of male predominance among abortuses with segmental mosaicism (Kovaleva, unpublished). In addition, in the group of apparently balanced carriers with no sex ratio distortion," there is a difference between males' and females' maternal ages (23.3 years vs 30.8 years), similar to that in groups with predominance of female carriers.

Additional studies on male to female ratios in prenatally diagnosed individuals and in preimplantation embryos would clarify this issue. Further studies on the origin and mechanisms of formation of mosaicism for structural chromosomal abnormalities are indicated.

\section{Conclusions}

The cytogenetic profile of phenotype-associated Reas (responsible for abnormal clinical features) shows a predominance for deletions of genetic material. Rearrangements of certain chromosomes may not be tolerated by the embryo while others, being involved in segmental mosaicism, might have a more favorable prospects. A significant female prevalence among carriers of mosaicism for loss of genomic material, as well as among carriers of mosaicism for both loss and gain of genomic material, suggests either a male-specific selection against abnormal cell line(s) or reduced viability of male fetuses. The absence of a skewed sex ratio in carriers of mosaicism for gain of genomic material may indicate that gains, despite being disease-causing, are tolerated in proliferating cells of male embryos unlike losses of genomic material. Maternal age might be a risk factor of occurrence of somatic mosaicism for structural Rea in female offspring or might cause an
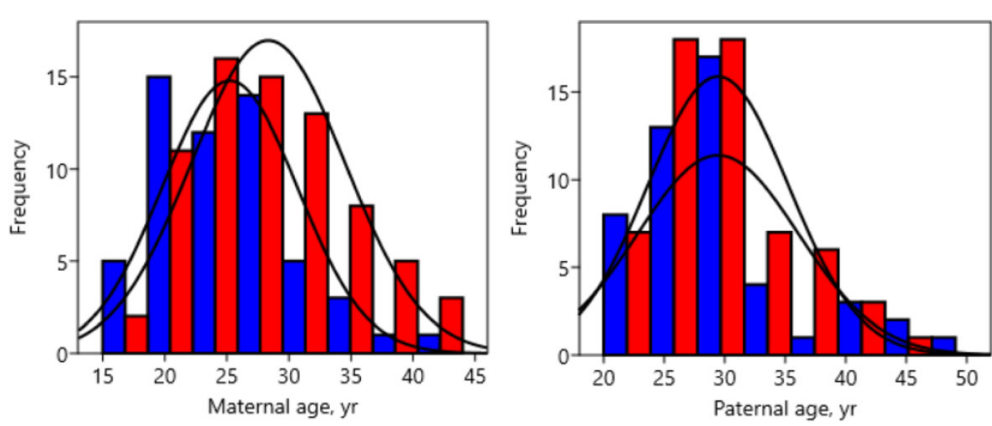

Fig. 2 Collation of histograms for the age of mothers of males (blue) and females (red) 
Table 5 Sex ratio in patients with segmental mosaicism according to maternal age

\begin{tabular}{|c|c|c|c|c|c|}
\hline \multirow{2}{*}{$\begin{array}{l}\text { Age groups, } \\
\text { years }\end{array}$} & \multicolumn{2}{|l|}{ Males } & \multicolumn{3}{|l|}{ Females } \\
\hline & Number & Proportion (P1) & Number & Proportion (P2) & Sex ratio $(\mathrm{P} 1 / \mathrm{P} 2$ \\
\hline$<20$ & 8 & 0.14 & 2 & 0.03 & 4.7 \\
\hline $20-24$ & 19 & 0.34 & 18 & 0.25 & 1.4 \\
\hline $25-29$ & 19 & 0.34 & 24 & 0.33 & 1.0 \\
\hline $30-34$ & 5 & 0.09 & 14 & 0.19 & 0.5 \\
\hline $35-39$ & 4 & 0.07 & 10 & 0.14 & 0.5 \\
\hline$\geq 40$ & 1 & 0.02 & 5 & 0.07 & 0.3 \\
\hline Total & 56 & 1.0 & 73 & 1.0 & \\
\hline
\end{tabular}

adverse effect on male embryo viability. Further evaluation of parental and cell origin of mosaic Rea would be advisable for elucidation of these intriguing subjects.

\section{Additional files}

Additional file 1:Table S1. Mosaicism for deletions. Tabular data presenting details of affected carriers of mosaicism for deletion: karyotype, parental ages at patient's birth, patient's age at ascertainment/ testing, proportion of abnormal cell line(s), and indications for cytogenetic testing. (XLSX $12 \mathrm{~kb}$ )

Additional file 2: Table S2. Mosaicism for duplications. Tabular data presenting details of affected carriers of mosaicism for duplication: karyotype, parental ages at patient's birth, patient's age at ascertainment/ testing, proportion of abnormal cell line(s), and indications for cytogenetic testing. (XLSX 8 kb)

Additional file 3: Table S3. Mosaicism for ring chromosomes. Tabular data presenting details of affected carriers of mosaicism for ring chromosome: karyotype, parental ages at patient's birth, patient's age at ascertainment/testing, proportion of abnormal cell line(s), and indications for cytogenetic testing. (XLSX $10 \mathrm{~kb}$ )

Additional file 4: Table S4. Mosaicism for unbalanced translocations. Tabular data presenting details of affected carriers of mosaicism for unbalanced translocation: karyotype, parental ages at patient's birth, patient's age at ascertainment/testing, proportion of abnormal cell line(s), and indications for cytogenetic testing. (XLSX $9 \mathrm{~kb}$ )

Additional file 5: Table S5. Mosaicism for other unbalanced rearrangements. Tabular data presenting details of affected carriers of mosaicism for other unbalanced rearrangement: karyotype, parental ages at patient's birth, patient's age at ascertainment/testing, proportion of abnormal cell line(s), and indications for cytogenetic testing. (XLSX 7 kb)

Additional file 6: Table S6. Mosaicism for apparently balanced rearrangements. Tabular data presenting details of affected carriers of mosaicism for apparently balance translocation or inversion: karyotype, parental ages at patient's birth, patient's age at ascertainment/testing, proportion of abnormal cell line(s), and indications for cytogenetic testing. (XLSX $6 \mathrm{~kb}$ )

Additional file 7: Table S7. Mosaicism due to rescued rearrangement Tabular data presenting details of affected carriers of mosaicism for rescued rearrangement: karyotype, parental ages at patient's birth, patient's age at ascertainment/testing, proportion of abnormal cell line(s), indications for cytogenetic testing, and description of method(s) of confirmatory study. (XLSX $7 \mathrm{~kb}$ )

Additional file 8: Table S8. Software used for the statistical data analysis. List of the programmes used for the data analysis, programme titles, version and/or date of release, URL, and references. (DOCX $17 \mathrm{~kb}$ )

Additional file 9: Reference list for Tables S1-S8. (DOCX $76 \mathrm{~kb}$ )

\section{Aknowledgement}

We wish to thank Dr. Nikita N. Khromov-Borisov (R.R.Vreden Russian Research Institute of Traumatology and Orthopedics) for statistical analysis of the data.

Funding

Not applicable.

Availability of data and materials

Data sharing not applicable to this article as no datasets were generated or analysed during the current study.

\section{Authors' contributions}

NVK and PDC performed the literature search, analyzed the data and wrote the manuscript. The authors alone are responsible for the content and writing of the paper. Both authors read and approved the final manuscript.

\section{Competing interests}

The authors declare that they have no competing interests.

\section{Consent for publication}

Not applicable.

Ethics approval and consent to participate

Not applicable.

\section{Publisher's Note}

Springer Nature remains neutral with regard to jurisdictional claims in published maps and institutional affiliations.

\section{Author details}

${ }^{1}$ Academy of Molecular Medicine, Mytniskaya str. 12/44, St. Petersburg 191144, Russian Federation. ${ }^{2}$ Department of Pediatrics, University of California San Francisco, San Francisco, CA, USA. ${ }^{3}$ ResearchDx Inc., Irvine, CA, USA.

Received: 17 March 2017 Accepted: 13 May 2017

Published online: 19 May 2017

\section{References}

1. Los FJ, Van Opstal D, van den Berg C. The development of cytogenetically normal, abnormal and mosaic embryos: a theoretical model. Hum Reprod Update. 2004;10:79-94.

2. Kovaleva NV, Cotter PD. Somatic/gonadal mosaicism for structural autosomal rearrangements: female predominance among carriers of gonadal mosaicism for unbalanced rearrangements. Mol Cytogenet. 2016;9:8.

3. Barber JCK. Directly transmitted unbalanced chromosome abnormalities and euchromatic variants. J Med Genet. 2005;42:609-29.

4. Kovaleva NV. Sex-specific chromosome instability in early human development. Am J Med Genet. 2005;36A:401-13.

5. Kovaleva NV. Nonmosaic balanced homologous translocations: some may be mosaic. Am J Med Genet. 2007;143A:2843-50. 
6. Molina O, Anton E, Vidal F, Blanco J. Sperm rates of $7 q 11.23,15 q 11 q 13$ and 22q11.2 deletions and duplications: a FISH approach. Hum Genet. 2011;129: $35-44$.

7. Thomas NS, Durkie M, Potts G, Sandford R, Van Zyl B, Youings S, Dennis NR, Jacobs PA. Parental and chromosomal origins of microdeletion and duplication syndromes involving 7q11.23, 15q11-q13 and 22q11. Eur J Hum Genet. 2006;14:831-7.

8. Sibbons C, Morris JK, Crolla JA, Jacobs PA, Thomas NS. De novo deletions and duplications detected by array CGH: a study of parental origin in relation to mechanisms of formation and size of imbalance. Eur J Hum Genet. 2012;20:155-60.

9. Feenstra I, Hanemaaijer N, Sikkema-Raddatz B, Yntema H, Dijkhuizen T, Lugtenberg D, Verheij J, Green A, Hordijk R, Reardon W, de Vries B, Brunner $H$, Bongers $E$, de Leeuw N, van Ravenswaaij-Arts C. Balanced into array: genome-wide array analysis in 54 patients with an apparently balanced de novo chromosome rearrangement and a meta-analysis. Eur J Hum Genet. 2011:19:1152-60.

10. Niebuhr E. Cytologic observations in 35 Individuals with a $5 p$ - karyotype. Hum Genet. 1978:42:143-56.

11. Robinson DO, Howarth DJ, Williamson KA, van Heyningen V, Beal SJ, Crolla JA. Genetic analysis of chromosome 11p13 and the PAX6 gene in a series of 125 cases referred with aniridia. Am J Med Genet. 2008; 146A:558-69.

12. Shinawi M, Liu P, Kang SH, Shen J, Belmont JW, Scott DA, Probst FJ, Craigen WJ, Graham BH, Pursley A, Clark G, Lee J, Proud M, Stocco A, Rodriguez DL, Kozel BA, Sparagana S, Roeder ER, McGrew SG, Kurczynski TW, Allison LJ, Amato S, Savage S, Patel A, Stankiewicz P, Beaudet AL, Cheung SW, Lupski JR. Recurrent reciprocal 16p11.2 rearrangements associated with global developmental delay, behavioural problems, dysmorphism, epilepsy, and abnormal head size. J Med Genet. 2010;47:332-41.

13. Munier F, Pescia G, Jotterand-Bellomo M, Balmer A, Gailloud C, Thonney F. Constitutional karyotype in retinoblastoma. Case report and review of literature. Ophthalmic Paediatr Genet. 1986;10:129-50.

14. Cassidy SB, Thuline HC, Holm VA. Deletion of chromosome 15 (q11-13) in a Prader-Labhart-Willi syndrome clinic population. Am J Med Genet. 1984;17: 485-95.

15. Kotzot D, Haberlandt E, Fauth C, Baumgartner S, Scholl-Bürgi S, Utermann G Del(18)(q12.2q21.1) caused by a paternal sister chromatid rearrangement in a developmentally delayed girl. Am J Med Genet. 2005;135A:304-7.

16. Guilherme RS, Klein E, Hamid AB, Bhatt $S$, Volleth M, Polityko A, Kulpanovich A, Dufke A, Albrecht B, Morlot S, Brecevic L, Petersen MB, Manolakos E, Kosyakova N, Liehr T. Human ring chromosomes - new insights for their clinical significance. Br J Med Genet. 2013;16:13-20.

17. Guilherme RS, Soares KC, Simioni M, Vieira TP, Gil-da-Silva-Lopes VL, Kim CA, Brunoni D, Spinner NB, Conlin LK, Christofolini DM, Kulikowski LD, Steiner CE, Melaragno MI. Clinical, cytogenetic, and molecular characterization of six patients with ring chromosomes 22, including one with concomitant 22q11.2 deletion. Am J Med Genet. 2014;164A:1659-65.

18. Fryns JP, Kleczkowska A, Smeets E, Van Den Berghe $H$. Transmission of ring chromosome 18 46, XX/46, XX, r(18) mosaicism in a mother and ring chromosome 18 syndrome in her son. Ann Genet. 1992;35:121-3.

19. Kleczkowska A, Fryns JP, Van den Berghe H. On the variable effect of mosaic normal/balanced chromosomal rearrangements in man. J Med Genet. 1990;27:505-7.

20. Sciorra LJ, Lee ML, Cuccurullo G. Translocation mosaicism in a woman having multiple miscarriages. Am J Med Genet. 1985;22:615-7.

21. Perfumo C, Cerruti Mainardi P, Cali A, Coucourde G, Zara F, Cavani S, Overhauser J, Bricarelli FD, Pierluigi M. The first three mosaic cri du chat syndrome patients with two rearranged cell lines. J Med Genet. 2000;37: 967-72.

22. Antonini S, Kim CA, Sugayama SM, Vianna-Morgante AM. Delimitation of duplicated segments and identification of their parental origin in two partial chromosome 3p duplications. Am J Med Genet. 2002;113:144-50.

23. Schluth C, Mattei MG, Mignon-Ravix C, Salman S, Alembik Y, Willig J, Ginglinger $E$, Jeandidier E. Intrachromosomal triplication for the distal part of chromosome 15q. Am J Med Genet. 2005;136:179-84.

24. Bonaglia MC, Giorda R, Beri S, Bigoni S, Sense A, Baroncini A, Capucci A, De Agostini C, Gwilliam R, Deloukas P, Dunham I, Zuffardi O. Mosaic 22q13 deletions: evidence for concurrent mosaic segmental isodisomy and gene conversion. Eur J Hum Genet. 2009;17:426-33.
25. Robberecht C, Voet T, Utine GE, Schinzel A, de Leeuw N, Fryns JP, Vermeesch J. Meiotic errors followed by two parallel postzygotic trisomy rescue events are a frequent cause of constitutional segmental mosaicism. Mol Cytogenet. 2012;5:19.

26. Vermeesch JR, Syrrou M, Salden I, Dhondt F, Matthijs G, Fryns JP. Mosaicism for duplication 12q (12q13 $\rightarrow 12 q 21.2)$ accompanied by a pericentric inversion in a dysmorphic female infant. J Med Genet. 2002;39:e72.

27. Melis D, Pia Sperandeo M, Perone L, Staiano A, Andria G, Sebastio G. Mosaic 13q13.2-ter deletion restricted to tissues of ectodermal and mesodermal origins. Clin Dysmorphol. 2006;15:13-8.

28. Freitas ÉL, Gribble SM, Simioni M, Vieira TP, Prigmore E, Krepischi AC, Rosenberg C, Pearson PL, Melo DG, Gil-da-Silva-Lopes VL. A familial case with interstitial 2q36 deletion: variable phenotypic expression in full and mosaic state. Eur J Med Genet. 2012;55:660-5.

29. Sánchez J, Fernández R, Madruga M, Bernabeu-Wittel J, Antiñolo G, Borrego S. Somatic and germ-line mosaicism of deletion 15q11.2-q13 in a mother of dyzigotic twins with Angelman syndrome. Am J Med Genet. 2014;164A:370-6.

30. Zollino M, Lecce R, Selicorni A, Murdolo M, Mancuso I, Marangi G, Zampino G, Garavelli L, Ferrarini A, Rocchi M, Opitz JM, Neri G. A double cryptic chromosome imbalance is an important factor to explain phenotypic variability in Wolf-Hirschhorn syndrome. Eur J Hum Genet. 2004;12:797-804.

31. Cody JD, Pierce JF, Brkanac Z, Plaetke R, Ghidoni PD, Kaye Cl, Leach RJ. Preferential loss of the paternal alleles in the 18q-syndrome. Am J Med Genet. 1997:69:280-6.

32. Phelan MC. Deletion 22q13.3 syndrome. Orphanet J Rare Dis. 2008;3:14.

33. Church DM, Yang J, Bocian M, Shiang R, Wasmuth JJ. Molecular definition of deletions of different segments of distal $5 p$ that result in distinct phenotypic features. Am J Hum Genet. 1995;56:1162-72.

34. Overhauser J, McMahon J, Oberlender S, Carlin ME, Niebuhr E, Wasmuth JJ, Lee-Chen J. Parental origin of chromosome 5 deletions in the cri-du-chat syndrome. Am J Med Genet. 1990;37:83-6.

35. Höckner M, Spreiz A, Frühmesser A, Tzschach A, Dufke A, Rittinger O, Kalscheuer V, Singer S, Erdel M, Fauth C, Grossmann V, Utermann G, Zschocke J, Kotzot D. Parental origin of de novo cytogenetically balanced reciprocal non-robertsonian translocations. Cytogenet Genome Res. 2012;136:242-5.

36. Grossmann V, Höckner M, Karmous-Benailly $H$, Liang D, Puttinger R, Quadrelli R, Röthlisberger B, Huber A, Wu L, Spreiz A, Fauth C, Erdel M, Zschocke J, Utermann G, Kotzot D. Parental origin of apparently balanced de novo complex chromosomal rearrangements investigated by microdissection, whole genome amplification, and microsatellite-mediated haplotype analysis. Clin Genet. 2010;78:548-53.

37. Molina O, Anton E, Vidal F, Blanco J. High rates of de novo 15q11q13 inversions in human spermatozoa. Mol Cytogenet. 2012;5:11.

38. Hehir-Kwa JY, Rodríguez-Santiago B, Vissers LE, de Leeuw N, Pfundt $R$, Buitelaar JK, Pérez-Jurado LA, Veltman JA. De novo copy number variants associated with intellectual disability have a paternal origin and age bias. Med Genet. 2011;48:776-8.

39. Johnson JP, Haag M, Beischel L, McCann C, Phillips S, Tunby M, Hansen J, Schwanke C, Reynolds JF. 'Deletion rescue' by mitotic 11q uniparental disomy in a family with recurrence of 11 q deletion Jacobsen syndrome. Clin Genet. 2014;85:376-80

40. Juberg RC, Stallard R, Mowrey P, Valido CL. Dissociation of a t(12;21) resulting in a normal cell line in two trisomic 21 sons of a nonmosaic $t(12$; 21) father? Hum Genet. 1983:64:216-21.

41. Jobanputra V, Wilson A, Shirazi M, Feenstra H, Levy B, Anyane-Yeboa K Warburton D. Partial uniparental disomy with mosaic deletion $13 q$ in an infant with multiple congenital anomalies. Am J Med Genet. 2013;161A:2393-5.

42. Kotzot D, Röthlisberger B, Riegel M, Schinzel A. Maternal uniparental isodisomy 11q13qter in a dysmorphic and mentally retarded female with partial trisomy mosaicism 11q13qter. J Med Genet. 2001;38:876-81.

43. Theophile D, de Blois MC, Barth D, Gilbert B, Picq M, Delabar J, Prieur M, Vekemans M. Partial correction of monosom y 21 by a duplication of chromosome 21. Am J Hum Genet. 1993;53 Suppl 3:610.

44. Gradek GA, Kvistad PH, Houge G. Monosomy rescue gave cells with normal karyotype in a mildly affected man with 46, XY, r(8) mosaicism. Eur J Med Genet. 2006:49:292-7.

45. Blouin JL, Aurias A, Creau-Goldberg N, Apiou F, Alcaide-Loridan C, Bruel A, Prieur M, Kraus J, Delabar JM, Sinet PM. Cytogenetic and molecular analysis of a de novo tandem duplication of chromosome 21. Hum Genet. 1991:88:167-74. 